\title{
ITT : THE MEDICO-LEGAL EVALUATION OF THE PSYCHOLOGICAL IMPACT ON THE VICTIMS OF TERRORIST ATTACKS IN FRANCE
}

WCP19-2262
Dr D. losub ${ }^{1}$, Dr E. Godard ${ }^{1}$, Dr A. De Herbay ${ }^{1}$, Dr D. Radji ${ }^{1}$, Dr A. Thiery ${ }^{2}$, Pr.Dr P. Vidailhet ${ }^{1}$

${ }^{1}$ University Hospital of Strasbourg, Service of Psychiatric Emergency, Strasbourg, France.

${ }^{2}$ Paul Strauss Center, Departement of Public Health, Strasbourg, France.

\section{Introduction}

For more than 20 years, a mental healthcare mobile unit, the Medico-psychological emergency unit (Cellule d'Urgence Médico-Psychologique: CUMP), was added to existing emergency services for mass casualty events. The CUMP is a French healthcare specificity and constitute a national network working with the prehospital emergency medical services in order to provide immediate intervention for collective psychological trauma

- The repetition of terrorist attacks is the origin of a reflection concerning the victimologica aspects. Individual rebuilding involves resilience at the individual, and community level, and is influnced by the government policies as part of financial reparation after acts of terrorism.

- In France, the harm is apprehended through a particular, specific notion of French law: the Tota Work Incapacity (Incapacité Totale de Travail: ITT). Its evaluation seems to represent a form of global scientific objectivity by recognizing the impact of the symptoms on psychological well being and everyday abilities. The ITT constitutes a basis for the assessment of damage, for the admissibility to the compensation commission and award of damages

Objectives of this descriptive, retrospective study was to use the ITT evaluation based on the psychiatric examinations of the victims after the terrorist attack in Strasbourg on 11 december 2018 to developpe a better understanding of the strengths and weaknesses of the ITT.

\section{Method}

Among 1263 persons seeking care for being exposed to the terrorist attack an initial medical certificate by judicial requisition was delivered for 71 victimes.

- The data were collected from a semi-structured national model of certificate used by CUMP to evaluate the psychological impact and to determine the duration of Total Work Incapacity

- The medical evaluation was carried out by psychiatrists from CUMP, the psychiatric emergency unit or other psychiatric departements and it included the initial symptomatology (day 0 to 3 ), the symptoms occurred between three days and one month, and the symptoms experienced 30 days or more following the traumatic event, the assessment of the psychological impact (mild, moderate, severe), the Clinical Global Impression (CGI) rating scale, as well as the duration of sick leave, and the medication if prescribed.

- We employed descriptive statistics using mean for univariables. Variables with significance of $p \leq 0.20$ in the univariate analyses were entered into a multivariate analysis.

\section{Results}

FIG 1 : Relation between ITT and the initial symptomatology

\begin{tabular}{|l|c|c|c|}
\hline \multicolumn{1}{|c|}{ ITT if symptom } & Present & Absent & P value \\
\hline Anxiety & 8,48 & 11,31 & 0,114 \\
\hline Crying & 10,38 & 8,85 & 0,303 \\
\hline Sadness & 10,5 & 9,09 & 0,143 \\
\hline Psychic sideration & 15,5 & 8,21 & 0,128 \\
\hline Confusion & 17,33 & 8,75 & 0,147 \\
\hline Derealization & $\mathbf{1 4 , 9}$ & $\mathbf{8 , 0 4}$ & $\mathbf{0 , 0 1 8}$ \\
\hline Automatic activity & 13,53 & 8,67 & 0,067 \\
\hline Sleep difficulties & $\mathbf{1 0 , 3 6}$ & $\mathbf{2 , 3 3}$ & $\mathbf{0 , 0 0 2}$ \\
\hline Difficulty concentrating & $\mathbf{1 2 , 4 6}$ & $\mathbf{7 , 2 5}$ & $\mathbf{0 , 0 0 3}$ \\
\hline Flash-back & $\mathbf{8 , 6 9}$ & $\mathbf{9 , 8 5}$ & 0,33 \\
\hline Avoidance & 10 & 8,5 & 0,387 \\
\hline Culpability & $\mathbf{1 7 , 0 5}$ & $\mathbf{6 , 0 1}$ & $\mathbf{0 , 0 0 0 4 5}$ \\
\hline
\end{tabular}

FIG 3 : Relation between ITT and medication, medical work leave FIG 2 : Relation between ITT and the persistant symptomatology

\begin{tabular}{|l|c|c|c|}
\hline \multicolumn{1}{|c|}{ ITT if symptom } & Present & Absent & P value \\
\hline Mild Anxiety & 11,9 & 9,034 & 0,418 \\
\hline Moderate Anxiety & 6,41 & 10,66 & 0,325 \\
\hline Severe Anxiety & 9,7 & 9,22 & 0,401 \\
\hline Inhibition & 4,6 & 10,1 & 0,456 \\
\hline Absence of Behavior Modification & 10,36 & 7,167 & 0,232 \\
\hline Automatic activity & 3,6 & 10,86 & 0,18 \\
\hline Emotional aenesthesia & 16 & 9,29 & 0,378 \\
\hline Repetitive memories & 9 & 9,86 & 0,445 \\
\hline Culpability & 13,44 & 8,36 & 0,259 \\
\hline Sleep difficulties & $\mathbf{1 1 , 3 4}$ & $\mathbf{6 , 3 7}$ & $\mathbf{0 , 0 2 8}$ \\
\hline Hyperarousal & 8,45 & 10,77 & 0,248 \\
\hline Exaggerated startle reactions & 4,78 & 11,78 & 0,075 \\
\hline Difficulty concentrating & 10,75 & 8,654 & 0,133 \\
\hline
\end{tabular}
and psychological impact

\begin{tabular}{|l|c|c|c|}
\hline \multicolumn{1}{|c|}{ ITT if symptom } & Present & Absent & P value \\
\hline Medication & 10,37 & 8,41 & 0,156 \\
\hline Medical work leave prescribed & $\mathbf{1 1 , 9 7}$ & $\mathbf{5 , 6 6}$ & $\mathbf{0 , 0 0 1 2}$ \\
\hline Severe Psychological impact & $\mathbf{1 9 , 2 3}$ & $\mathbf{6 , 3 9}$ & $\mathbf{0 , 0 0 0 1 5}$ \\
\hline Moderate Psychological impact & $\mathbf{9 , 1}$ & $\mathbf{9 , 3 2}$ & 0,312 \\
\hline Mild Psychological impact & $\mathbf{3 , 0 8 7}$ & 12,31 & 1,04 \\
\hline
\end{tabular}

\section{FIG 4 : Relation between ITT and CGI}

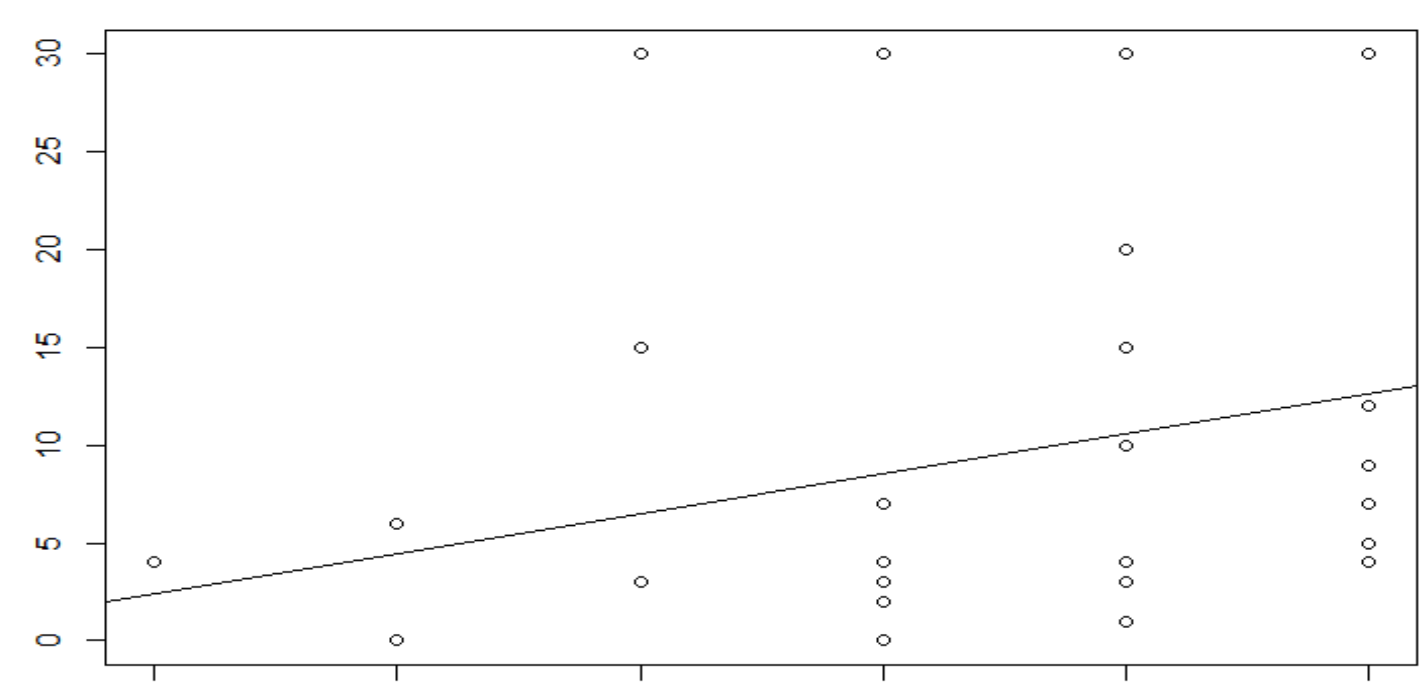

CGI

- The results suggest that there is a better fiability for the ITTs longer than 10 days. The elevated duration of ITT (between 10 et 30 days) appears to be decided by the psychiatrist working to CUMP, which could evaluated the victims with more severe symtoms. The delay between the traumatic event and the psychiatric evaluation was not correlated with the importance of ITT.

The multivariate analysis evidence that the culpability was associated with an increase by 10 days of ITT $(p=0.0002)$ and the mild psychological impact with a decreased by 8 days of ITT $p=0.00157$ ) all else equal.

\section{Discussion - Conclusion}

The ITT represent an instrument used to evaluate the psychological and physical incapacity of victimes of different traumatismes. Going beyond the singular doctor patient relationship, the evaluation offers a space to the therapeutic and reparation beginnings. The intervention takes into account a multidimensional dynamic of testimony, recognition, reparation in a contemporary societal functioning where the post-traumatic psychic trace becomes the proof of the reality of the facts anc thus appears inseparable from the dynamics of repair

The medical evaluation can not ignore that the status of the victim is the subject of societal / medical / political chalenges and has to consider the phenomenon of " moral conversion » with the passage from suspicion to recognition, from disqualifications to legitimacy, from pathological to heroic, from individual inadequacy to individual and collective resilience

Our findings evidence a high interexaminer reliability for the subjects which present severe fonctional impairements, especially culpability ( $p=0.00045$ ), and dissociation $(p<0.05)$. In the presence of a moderate and mild symptomatology, the subjectivity of the examinator seems to take a more important place.

To have clinical utility, it is imperative that examination results, interpreted by different clinicians, have high interexaminer reliability. As the medical certificate is used in the complexe process of judicial qualification of the facts, recognition and adequate compensation, it expected to be explanatory, normative, objective, precise, and reproducible.

The results of this study suggest that a variety of information-gathering strategies contribute to determine the ITT actually. They emphasize that a higher degree of standardization is required to obtain a stronger reliability. A standardized instrument with a high specificity and sensitivity seems necessary in order to realize a better assessment focused on psychological impact among victimes of traumatic events. 